\title{
The Role of Allergens in Atopic Dermatitis
}

öz

Atopik dermatit, genetik ve çevresel faktörlerin etkisinde gelişen, çoğunlukla süt çocukluğu döneminde başlayan kronik bir cilt hastalığıdır. Atopik yürüyüş olarak tanımlanan sürecin en baştaki basamağıdır. Astım ve alerjik rinit gibi alerjik hastalıkların gelişiminin erken işareti olabilir. Özellikle atopisi olan gıda ve inhalan alerjenlere duyarlılık saptanan hastalarda diğer atopik hastalıkların ortaya çıkması daha sık görülür. Bu duyarlanmaların atopik dermatit'teki rolü tartışmalı olsa da hastaların bir kısmında egzematöz deri lezyonlarını tetikleyebileceği belirlenmişsir. Bu derlemede, atopik dermatitte alerjenlerin rolü güncel literatür eşliğinde değerlendirilmiştir.

Anahtar kelimeler: Atopik dermatit, alerjen, çocuk, besin alerjisi

\section{ABSTRACT}

Atopic dermatitis is a chronic skin disease that develops under the influence of genetic and environmental factors and usually starts in infancy. It is the first step of the process defined as atopic march. It can be an early sign of the development of allergic diseases such as asthma and allergic rhinitis. Especially in patients with atopic sensitivity to food and inhalant allergens, the emergence of other atopic diseases is more common. Although the role of these sensitivities in atopic dermatitis is controversial, it has been determined that some patients may trigger eczematous skin lesions. In this report, the role of allergens in atopic dermatitis are reviewed in the light of current literature.
Received/Geliş: 05.02.2019

Accepted/Kabul: 04.08.2020

Published Online: 22.12.2020

Suna Asilsoy Dokuz Eylül Üniversitesi Tıp Fakültesi, Çocuk Alerji ve Immunoloji Bilim Dalı, İzmir, Türkiye

- suna.asilsoy@deu.edu.tr ORCiD: 0000-0002-4235-0995

S. Al 0000-0002-4846-6761 Dokuz Eylül Üniversitesi Tıp Fakültesi, Çocuk Alerji ve Immunoloji Bilim Dalı, Izmir, Türkiye

Keywords: Atopic dermatitis, allergen, children, food allergy

\section{GiRiş}

Atopik dermatit $(A D)$, uzun yıllar sadece klinik bir tanımlama olarak bilinmiş, son dönemlerde yapılan çalışmalarla etiyoloji ve patogenezinde önemli ilerlemeler sağlanmıştır. 20. yüzyılda egzemanın alerjik rinit ve astımla birlikteliğinin saptanması "alerjik triad" olarak tanımlanmasına neden olmuştur. Atopik dermatit 1933 yılında Wise ve Sulzburger ${ }^{(1)}$ tarafından iyileşme ve alevlenme dönemleri ile seyreden, derinin inflamatuar ve kronik bir hastalığı olarak tanımlanmıştır. Prevalansının çocuklarda \% 15-20, yetişkinlerde \%1-3 olduğu tahmin edilmektedir ve insidansı son yıllarda sanayileşmiş ülkelerde 2-3 kat artmıştır (2).

Klinikte iki farklı egzama varyantı tanımlanabilir: bunlardan biri atopik olan, daha çok çocuk ve genç erişkinlerde görülen, altta yatan inflamasyonda total IgE yüksekliği ve IgE ilişkili reaksiyonların olduğu "atopik form" diğeri ise yüksek spesifik IgE içermeyen yani alerjenin olmadığı "nonatopik form"dur.

Atopik olan form atopik yürüyüşün ilk bulgusu olup batı tarzı yaşayan toplumlarda daha sık görülür genellikle erken bebeklik dönemde başlar ve sıklığı \%20-25 arasındadır ${ }^{(2,3)}$. Bu tipte erişkin başlangıçlı AD daha nadirdir (etkilenen erişkinlerin \%9-14) ${ }^{(4)}$. Etkilenen bireylerin \%85'inde 5 yaşından önce, \%60'ında yaşamın ilk yıllarında görülür ${ }^{(3)}$. Alerjenlere gelişen erken duyarlııı ve hastalığın ağır olması $A D^{\prime}$ in persistan olmaya hatta yaşam boyu sürmeye eğilimli olduğunu gösteren bir bulgudur.

Non-atopik dermatit (intrensek, IgE kaynaklı olmayan) terimi ise IgE duyarlanması ile ilişkisiz atopik dermatiti tanımlar. Bu grupta, atopik olan çocuklara göre astım gelişme riski daha düşüktür. Okul öncesi çocuklarda ve erişkinlerde daha sıktır. AD olan çocuklarda non-atopik dermatit \%45-65, erişkinlerde ise $\% 40$ olarak saptanmıştır ${ }^{(5,6)}$.

(c) Telif hakkı İzmir Dr. Behçet Uz Çocuk Hastalıkları ve Cerrahisi Eğitim ve Araștırma Hastanesi'ne aittir Logos Tıp Yayıncılık tarafindan yayınlanmaktadır.

Bu dergide yayınlanan bütün makaleler Creative Commons Atf-GayriTicari 4.0 Uluslararası Lisansı ile lisanslanmıştır.

(C) Copyright İzmir Dr. Behçet Uz Children's Hospital. This journal published by Logos Medical Publishing.

Licenced by Creative Commons Attribution-NonCommercial 4.0 International (CC BY-NC 4.0) 


\section{Atopik Dermatitte Alerjenlerin Rolü}

$A D$, deri bariyerinde defekte ve bozulmuş immun yanıta neden olan genetik yatkınlık ile alerjen, iritan ve mikroplar gibi çeşitli çevresel tetikleyiciler arasındaki kompleks patolojik etkilenme sonucu oluşur ${ }^{(7)}$. Hastalığın altta yatan nedeni tam olarak anlaşılamasa da son yıllarda alerjenlerin rolü daha çok açıklığa kavuşmuştur. Özellikle çocuklarda alerjik komponentlerin önemini gösteren pek çok bulgu elde edilmiştir. Alerjenlerin birçoğu suçlanmakla birlikte çalışmaların büyük bir kısmı gıda alerjileri (GA) üzerine odaklanmıştır.

Genetik yatkınlık $A D^{\prime}$ in patogenezinde çok önemli rol oynar. Çoğunluğu deri bariyer fonksiyonunu kodlayan, ayrıca innate ve adaptif immun yanıtta rol oynayan çeşitli genler tanımlanmıştır ${ }^{(8)}$. Bir epidermal yapısal protein olan filagrini (FLG) kodlayan genin mutasyonun epidermal disfonksiyonda anahtar rol oynadığı ve AD riskinde artışa neden olduğu gösterilmiştir ${ }^{(9)}$. Filagrin, AD'de genetik bağlantısı en çok araştırılan proteindir. Ancak yine de FLG mutasyonu ile $A D$ arasındaki ilişkide aydınlatılamayan noktalar vardır. AD'li hastaların hepsinde FLG mutasyonu yoktur, ya da FLG mutasyonu olan hastaların bir kısmında $A D$ yoktur. Ancak FLG mutasyonu olan ve $A D$ olan hastalarda hastalık erken başlangıçlı, ağır ve persiste olmaya eğilimlidir. Bu hastalarda alerjik duyarlanma ve astım daha fazladır ${ }^{(10)}$. Güncel yapılmış çalışmalarda deri bariyer fonksiyonu (yani FLG, FLG - 2, SPINK5) ve doğal/adaptif bağışıklık (yani IL 4, IL - 13, DEFB1) ile ilişkili genlerdeki mutasyonların sıklığı ve türündeki değişikliklerin, $A D^{\prime}$ in insidansını ve ciddiyetini etkileyebileceği gösterilmiştir8. Epidermal bariyer fonksiyon bozukluğu $A D^{\prime}$ in önemli bir özelliğidir. Bu olay transepidermal su kaybı yanı sıra alerjenler, mikroorganizmalar, iritanlar gibi çeşitli tetikleyicilerin cilde penatrasyonunu sağlayarak immun sistem ile ilişki kurmasında önemli rol oynamaktadır. Çevresel aeroalerjenlerin yanı sıra cilde lokal uygulanan gıda proteinleri içeren maddelerin kullanılmasıyla yani temas yolu ile de gıda alerjisi gelişebilmektedir. Alerjene maruziyetten sonra deride inflamatuar yanıt modelinde yüksek afiniteli IgE reseptörleri bulunan epidermal antijen sunucu hücreler (dentrik hücre ve Langerhans hücreler) antijeni bağlayarak Th2 hücrelere sunar ve lokal inflamasyo- na neden olur ${ }^{(11)}$.

GA'da duyarlılık çoğunlukla gastrointestinal yolak ile olur. Dolaşım içerisinde işlenmemiş proteinlerin absorbsiyonu hem atopik hem de non-atopiklerde görülen fizyolojik bir olaydır. Gıda alerjili AD'li çocuklarda deri bariyerindeki bozukluğa benzer şekilde barsak bariyer disfonksiyonunun olması da duyarlanmada rol oynayabilir. AD'li hastalarda barsak epitel hücrelerinde bulunan IgE'nin, absorbsiyonu kolaylaştırdığı ve barsak bariyerinden geçişin kolaylaştığı gösterilmiştir. Hızlı absorbe edilen gıda proteinleri deride immun yanıtı başlatabilir ve arttırabilir ${ }^{(12)}$.

AD'li hastada deride bir alerjene immun yanıt, IgE kaynaklı ani ve $T$ hücre kaynaklı geçikmiş tipte aşırı duyarlılık reaksiyonlarının rol oynadığı karmaşık bir olaydır ${ }^{(11)}$.

\section{Atopik Dermatit ve Gıda Alerjileri}

AD de GA'lerinin rolü 1900 yılların başında suçlanan gıdanın kesilmesi ile semptomların düzeldiği, gıdanın tekrar başlanması ile bulguların yeniden başladığı olgu sunumlarında gösterilmiştir ${ }^{(13)}$. Son yıllarda iyi tanımlanmış çalışmalar ile bir grup hastada GA'lerinin AD'de önemli rol oynadığı, suçlanan gıdanın eliminasyonu ile semptomların gerilediği, provokasyon ile bulguların başladığı ve eliminasyonun semptomların düzelmesinde yardımcı olduğu gösterilmiştir ${ }^{(14)}$.

Diğer kronik atopik hastalıklarda olduğu gibi $A D^{\prime} l i$ hastalarda da çok çeşitli tetikleyicilerin katkısı prevelans çalışmalarında güçlüğe neden olmaktadır. Batı tarzı yaşam stili olan toplumlarda GA sıklığı \%5-10 belirlenmiş ve zamanla sıklığında artış olduğu saptanmıştır ${ }^{(15)}$. AD'li hastalarda yaşa ve hastalık şiddetine göre değişmekle birlikte bu oran çok daha yüksektir. Çalışmalarda yöntemsel farklılıktan dolayı farklı sonuçlar bulunsa da çift kör plasebo kontrollü çalışmalarda orta-ağır AD çocukların yaklaşık üçte birinde gıda alerjisi olduğu gösterilmiştir (16). Erişkinlerde yeterli sayıda hasta değerlendiren prevelans çalışmaları eksik olmakla birlikte GA'nin daha az rol oynadığı düşünülmektedir ${ }^{(17)}$.

\section{Tetikleyen Gıdalar}

AD'li hastalarda yumurta, süt, buğday, soya, fıstık, 
kabuklu ağaç fındıkları ve balık hastaların >\%90'ından fazlasında sorumludur ${ }^{(18)}$. Hastanın yaşına göre suçlanan gıda maddeleri Tablo 1'de gösterilmiştir.

Tablo 1. Yaşa göre sıklıkla gıda alerjisine neden olan gıdalar.

\begin{tabular}{lll}
\hline İnfant & Çocuk (2-10 yaş) & Adolesan ve genç erişkinler \\
\hline Süt & Süt & Fıstık \\
Yumurta & Yumurta & Ağaç fındıkları \\
Buğday & Fıstık & Balık \\
Soya & Ağaç fındıkları & Kabuklu deniz ürünleri \\
& Balık & Susam \\
& Kabuklu deniz ürünleri & Polen ilişkili gıdalar \\
& Susam & \\
& Kivi & \\
\hline
\end{tabular}

Sıklıkla suçlanan klasik gıda proteinlerinin yanı sıra diğer gıda komponentleride bazı kişilerde $A D^{\prime}$ in alevlenmesine neden olabilir. Bu reaksiyonların alerjik mi yoksa non-alerjik (psödoalerjik) reaksiyonlar mı olduğu henüz kesinlik kazanmamıştır ${ }^{(19)}$.

Huş polen duyarlılığı olan hastalarda oral gıda provokasyon testleri sırasında çapraz reaksiyon gösteren gıdalar ile etkileşim sonucu egzemaları alevlenebilir. Polen ilişkili gıdalar tarafından AD alevlenmesi nadir olup adolesan ve erişkin hastalarda daha sık görülür ${ }^{(20)}$.

\section{AD'li Hastalarda Gıdalara Karşı Gelişen Reaksiyonlar \\ Oral gıda provokasyonları sırasında 3 tip reaksiyo-} nun geliştiği görülmüştür. Bunlar;

1. Ani gelişen tip (immediate-type): Genellikle IgE kaynaklıdır ve suçlanan gıda maddesinin alımını takiben 2 saat içerisinde ürtiker, angioödem, kızarıklık, kaşıntı, gastrointestinal veya respiratuvar yolakta ani gelişen diğer reaksiyonlar veya anafilaksi şeklinde bulgu verir ${ }^{(21)}$. Cilt bulguları hastaların \%74'ünde görülür, ayrıca başlangıçta ani gelişen reaksiyondan 4-6 saat sonra geçici bir döküntü gelişebilir. Bu durum geç faz IgE kaynaklı reaksiyon olarak adlandırılır.

2. Geç tip reaksiyonlar (non-IgE kaynaklı): İzole egzematöz reaksiyonlar olup suçlanan gıda maddeleri ile yapılan provakasyondan 6-48 saat sonra AD için etkilenmesi beklenen bölgelerde lezyonların aktive olması şeklinde bulgu verir. Bu tip reaksiyonları değerlendiren az sayıda çalışma vardır. Reaksiyonların
$\% 2$ 'si oral provakasyondan sonra 2 saat içerisinde, $\% 10$ 'nunda ise 16 saat sonra görülür (21).

3. Kombine tip (Miks Tip): Ani gelişen reaksiyonu takiben egzematöz geç-tip reaksiyon gelişmesi oral provokasyon testi pozitif olan hastaların \%40'ında görülür ${ }^{(22)}$.

\section{Atopik Dermatitli Hastalarda Gıda Alerjisinde Tanısal Yaklaşım \\ Öncelikle detaylı öykü alınıp fizik muayene yapıl-} malı daha sonra in-vitro ve in-vivo testler SplgE ölçümü, deri prik testi, atopi yama testi, tanısal eliminasyon diyeti ve/veya oral yükleme testleri yapılmalıdır (22) (Şekil 1'de yaklaşım özetlenmiştir).

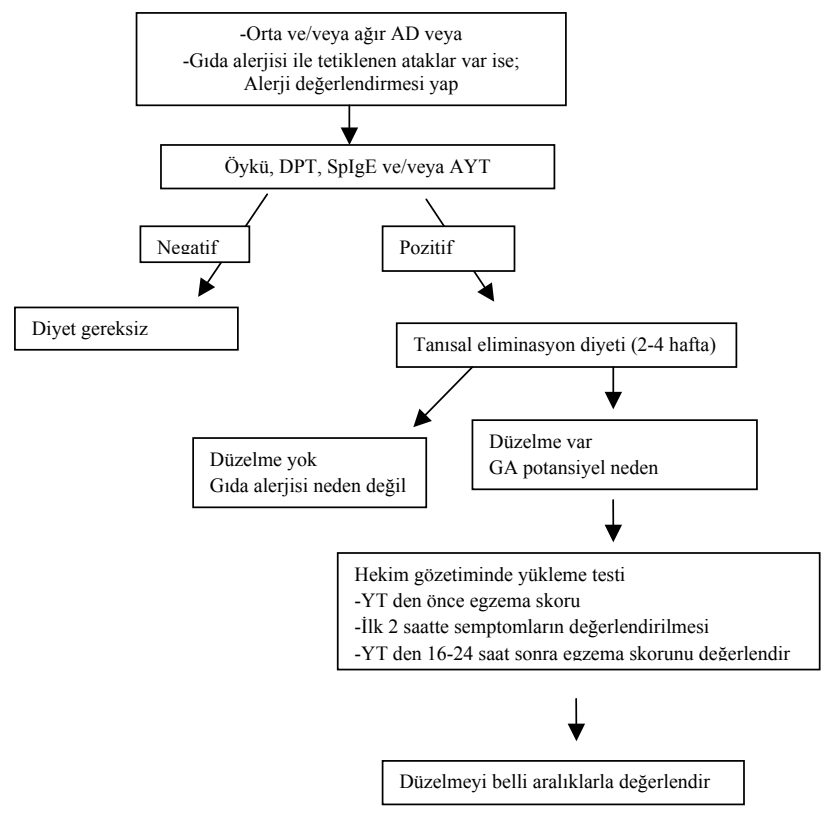

Şekil 1. Gıda alerji değerlendirilmesinde tanısal yaklaşım (kısaltmalar: DPT: deri prik testi, AYT: Atopi yama testi, SplgE: spesifik IgE, YT: yükleme testi).

Şüphelenilen gıda maddesinin alımını takiben gelişen reaksiyonların ani tipte ya da geç başlangıçlı mı olduğu değerlendirilmelidir. Ani tip reaksiyonların pozitif öykülü bireylerde pozitif prediktivite değeri geç tip reaksiyonlardan daha yüksektir. Hastalar ve ebeveynler egzema alevlenmesinde sıklıkla belirli gıdaları suçlamaktadır. Ancak alevlenmeye neden olan diğer faktörlerin varlığı unutulmamalıdır. Bir çalışmada ebeveynler tarafından suçlanan gıdalarla yapılan provakasyonda hastaların yalnızca \%35-40'ın da pozitiflik saptanmıştır (23). 
Deri prik testleri ilk basamak testlerdir. Test edilecek gıdalar öyküye ve hastanın yaşına göre seçilmelidir (21) (Tablo 2'de yaşa göre deri testi yapılması önerilen alerjenler özetlenmiştir). Bu testlerin negative prediktivite değeri yüksek (\%95) pozitif prediktivite değeri ise düşüktür (\%40) ${ }^{(23)}$. Bazı gıda maddelerinin alerjisinde kullanılan eşik düzeyleri dikkate alındığında oral gıda provakasyonu ile karşılastırıldığında hastaların \%95'inde tanıda yardımcı olabileceği gösterilmiştir. Ayrıca serum SplgE düzeylerindeki yükseklik oral gıda provakasyonu yapılması için kontrendikasyon değildir ${ }^{(24)}$.

Atopik yama testi rutin klinik pratikte kullanımı önerilmemektedir ${ }^{(25)}$. Duyarlılığı düşüktür ${ }^{(26)}$.

Standartize Oral Gıda Provakasyon Testi tanıda altın standart testlerdir. Önerilen, testin çift kör plasebo kontrollü olarak yapılmasıdır ${ }^{(25)}$ (Şekil 2'de oral gıda provakasyonu sırasında önerilen standart protokol gösterilmiştir).

Tablo 2. Yaşa göre AD'li hastalarda alerji testleri.

\begin{tabular}{ll}
\hline$<3-4$ yaş & $>3-4$ yaş \\
\hline Gıdalar & Gıdalar \\
- Süt & -Süt \\
- Yumurta & -Yumurta \\
- (Fıstık, buğday, ağaç fındıkları) & -Fıstık \\
& -Buğday, ağaç fıstıkları, balık \\
& \\
İnhalen Alerjenler & Inhalen Alerjenler \\
- Ev tozu & -Ev tozu \\
- Kedi, kopek & -Kedi, kopek \\
- Polen & -Polen
\end{tabular}

Yükleme testinde önce

-Kuşkulu gıdanın en az 3 hafta eliminasyonu -Sistemik ilaçaları kes

Egzemayı değerlendir (SCORAD)

Deneyimli ekip tarafından hesaplanan doz 2 kat arttırılarak 15-30 dk. aralarla (toplam 3-6 basamak) 2 saat içerisinde verilir. Her basamakta semptomları değerlendir.

Egzema ağrılığı için en az 16-24 saat değerlendir (SCORAD).

Şekil 2. AD'li hastalarda gıda yüklemesi için önerilen standart protokol.

\section{Atopik Dermatit ve Gıda Alerjili Hastanın Tedavisi}

$A D^{\prime} l i$ hasta potansiyel tetikleyiciler için değerlendirilirken uygun cilt bakımıda yapılmalıdır. Çevresel tetikleyiciler ve iritanlardan hastalar kaçınmalıdır.

Semptomlarının alevlenmesine neden olan gıda maddesi saptanan hastaların diyetlerinden bu gıdanın uzaklaştırılması düzelme sağlayacaktır. Ancak eliminasyon için süre ve kısıtlamanın etkisi halen tartışmalı bir konudur. Çünkü gıda eliminasyonundan sonra hastada görülen reaksiyonun tipi değişerek kazara alımlarda bile potansiyel olarak hayati tehlikesi olabilen IgE kaynaklı reaksiyon gelişebileceği bildirilmiştir (27). Bunu önlemek için AD alevlenmesine neden olan gıdanın tolere edilebildiği kadar alınması ve $A D^{\prime}$ in tedavisinin yapılması önerilmektedir. Eliminasyon diyetinin faydası ve zararları için aile ile tartışılarak karar verilmesi gereklidir ${ }^{(22)}$.

\section{Takip ve Prognoz}

$A D^{\prime}$ li çocukların üçte birinde tanıdan 1-3 yıl sonra GA düzelmektedir. Süt, yumurta buğday ve soya alerjisi hastaların çoğunda kısa sürede düzelme eğilimi gösterir. Bu hastaların aralıklı takibi gerekebilir. Gıda SplgE düzeyleri takip için faydalı olabilir. Ancak klinik bulgular kısa sürede de düzelebilir bu nedenle oral provakasyon testleri toleransı değerlendirmek için de yapılmalıdır ${ }^{(21,22)}$.

Fıstık, ağaç fındıkları, balık, kabuklu deniz ürünlerine alerjik hastalarda klinik bulguların düzelmesi daha nadir gözükür ${ }^{(28)}$. GA'li hastaların takibinde deri prik testleri faydalı değildir, çocuğun suçlanan gıdayı almasına ragmen klinik bulgular düzeldiği halde uzun yıllar test pozitif kalabilir.

\section{Atopik Dermatit ve Aeroalerjenler}

GA prevelansı 3 yaşından sonra giderek azalırken inhalen alerjenlere duyarlılıkta artış gözlenmektedir. Orta-ağır AD'li çocuklarda, astımlı veya nonatopik kontrollere göre akar, hayvan tüyleri, küf mantarı ve mayalara pozitif SplgE yanıtı daha fazla saptanmıştır (29). Bu sensitizasyonların $A D^{\prime}$ de rolü tartışmalı olsa da bazı hastalarda belirli inhalen alerjenlerle temas egzematöz deri lezyonlarını tetikleyebilir.

İnhalen alerjenlerin AD'deki rolü gıda alerjileri 
kadar araştırılmamıştır. 1918'de Walker ve ark. ${ }^{(30)}$ AD'li bazı hastalarda aeroalerjenlerle temas sonrası cilt lezyonlarında alevlenme olduğunu göstermiştir. Daha sonraki yıllarda erişkin hastaların çoğunda akara karşı deri testinde pozitiflik olduğu aeroalerjenler ile nazal provakasyon sonrası cilt lezyonlarının aktive olduğu, akara maruziyeti azaltan önlemler ile deri lezyonlarının düzelebileceği gösterilmiştir ${ }^{(31)}$. Daha sonra çift kör randomize plasebo kontrollü bir çalışmada akarlar ile yapılan bronkoprovakasyon sonrası yeni başlayan AD deri lezyonları ve daha önce olan lezyonların alevlenebileceği gösterilmiştir (32). Bütün bu çalışmalar aeroalerjenler ile $A D^{\prime}$ 'in alevlenmesinde ve başlamasında respiratuvar yolun önemli olabileceğini desteklemektedir.

Atopi yama testleri AD'de inhalan alerjenlerin varlığının değerlendirilmesinde uygulanmış olup hastaların bir grubunda bu testler sırasında egzematöz reaksiyonların ortaya çıktığı gösterilmiştir ${ }^{(33)}$. AD'li hastalarda akar, polen, hayvan tüyleri ve küfe karşı pozitif reaksiyon saptanmış, sağlıklı ve respiratuar alerjili hastalarda pozitiflik oranının daha nadir olduğu gösterilmiştir ${ }^{(34)}$. Bu da aeroalerjenlere sensitizasyonda cilde temas yoluyla da duyarlılığın gelişebileceğini desteklemektedir.

Hücresel düzeyde yapılan çalışmalarda AD'de ciltte areoalerjenlerin rolü alerjen spesifik IgE'lerin ve alerjen spesifik T hücrelerinin saptanması ile gösterilmiştir ${ }^{(35)}$.

\section{Tanı}

GA'ne benzer şeklide öykü, deri prik testi ve splgE ölçümleri ve AYT uygulaması ile alerji varlığı değerlendirilmelidir. Hastanın yaşına ve öyküsüne göre akar, polen, hayvan tüyleri ve küf mantarlarını içeren alerjenlere duyarlılık deri prik testi ve splgE ile değerlendirildikten sonra negatif olan hastalarda AYT uygulanmalıdır. Avrupa Alerji ve Klinik İmmunoloji (EAACI) ${ }^{(21,25)}$. Akademisi aeroalerjenler ile ilişkili semptomların varlığında deri prik testi ve splgE negatif ise tetikleyicileri bilinmeyen orta-ağır $A D$ varlığında $A D^{\prime}$ li hastalarda, klinik önemi olmayan çoklu IgE duyarlanmasında AYT yapılmasını önermektedir.

AYT özellikle nonatopik egzemalı hastalarda klinik bulguların artmasına sebep olan faktörlerin saptan- masında önemli rol oynamaktadır. Bu testeki en büyük problem standartizasyonun olmamasıdır ${ }^{(26,36)}$.

\section{Tedavi}

Aeroalerjenlerden kaçınmanın AD semptomlarını düzelmesinde etkili olduğu özellikle akar alerjisinde yapılan çalışmalarda gösterilmiştir ${ }^{(37,38)}$. Kaçınmaya ek olarak spesifik immunoterapinin alerjik rinit ve astım varlığına eşlik eden $A D^{\prime}$ 'in tedavisinde etkili olabileceğini gösteren çalışmalar bildirilmiştir ${ }^{(39)}$.

Sonuç olarak, ADli hastaların bir kısmında gıda ve inhalen alerjenler semptomların tetiklenmesinde önemli rol oynayabilir. Özellikle orta-ağır şiddette $A D$ olan standart tedavi ile kolay kontrol altına alınamayan, sık tekrarlayan alevlenmeleri olan hastalarda alerjenlerin varlığı araştırılmalıdır. Gıda alerjilerinin etkisi daha çok gösterilmiş olsa da bu hastaların bir kısmında şüpheli gıdaların eliminasyonu konusunda daha dikatli davranılmalı, tanı koyabilmek için gerekli hastalardsa SplgE, deri prik testi, atopi yama testi ve provokasyon testleri yapılmalıdır.

Çıkar Çatışması: Yoktur.

Finansal Destek: Yoktur.

Conflict of Interest: None.

Funding: None.

\section{KAYNAKLAR}

1. Wise F, Sulzberger M. Eczematous eruptions. Year Book of Dermatology and Syphilogy. Chicago: Year Book Medical; 1933.

2. Nutten S. Atopic Dermatitis: Global Epidemiology and Risk Factors. Ann Nutr Metab. 2015;66(suppl 1):8-16. https://doi.org/10.1159/000370220

3. Weidinger S, Novak N. Atopic dermatitis. Lancet. 2016;387:1109-22. https://doi.org/10.1016/S0140-6736(15)00149-X

4. Ozkaya E. Adult-onset atopic dermatitis. J Am Acad Dermatol. 2005;52:579-82. https://doi.org/10.1016/j.jaad.2004.11.037

5. Bohme M, Wickman M, Lennart Nordvall $S$, et al. Family history and risk of atopic dermatitis in children up to 4 years. Clin Exp Allergy. 2003;33(9):1226-31.

https://doi.org/10.1046/j.1365-2222.2003.01749.x

6. Schmid-Grendelmeier $\mathrm{P}$, Simon $\mathrm{D}$, Simon $\mathrm{HU}$, et al. Epidemiology, clinical features, and immunology of the "intrinsic" (non-IgE-mediated) type of atopic dermatitis (constitutional dermatitis). Allergy. 2001;56(9):841-9. https://doi.org/10.1034/j.1398-9995.2001.00144.x

7. Bergman MM, Caubet J-C, Boguniewicz M, Eigenmann PA. 
Evaluation of food allergy in patients with atopic dematitis. J Allergy Clin Immunol: In Practice. 2013;1:22-8. https://doi.org/10.1016/j.jaip.2012.11.005

8. Kaufman BP, Guttman-Yassky E, Alexis AF. Atopic dermatitis in diverse racial and ethnic groups-Variations in epidemiology, genetics, clinical presentation and treatment, Exp Dermatol. 2018;27(4):340-57. https://doi.org/10.1111/exd.13514

9. Paternoster $L$ et al. Multi-ancestry genome-wide association study of 21,000 cases and 95,000 controls identifies new risk loci for atopic dermatitis, Nat Genet. 2015;47(12):1449-56. https://doi.org/10.1038/ng.3424. Epub 2015 Oct 19.

10. Weidinger $S, O^{\prime}$ Sullivan $M$, Illig $T$, Baurecht $H$, Depner $M$, Rodriguez $\mathrm{E}$, et al. Filaggrin mutations, atopic eczema, hay fever, and asthma in children. J Allergy Clin Immunol. 2008;121:1203-9.e1.

https://doi.org/10.1016/j.jaci.2008.02.014

11. Weidinger S, Beck LA, Bieber T, Kabashima K, Irvine AD. Atopic dermatitis. Nat Rev Dis Primers. 2018;4(1):1. https://doi.org/10.1038/s41572-018-0001-z

12. Longo G, Berti I, Burks AW, Krauss B, Barbi E. IgE-mediated food allergy in children. Lancet. 2013;382:1656-64. https://doi.org/10.1016/S0140-6736(13)60309-8

13. Schloss OM. Allergy to common foods. Trans Am Pediatr Soc. 1915;27:62-8.

14. Fergusson DM, Horwood LJ, Shannon FT. Early solid feeding and recurrent childhood eczema: a 10-year longitudinal study. Pediatrics. 1990;86(4):541-6.

15. Savage, Jessica, and Christina B Johns. Food allergy: Epidemiology and natural history. Immunology and Allergy Clinics of North America. 2015;35(1):45-59. https://doi.org/10.1016/j.iac.2014.09.004

16. Sampson HA. The evaluation and management of food allergy in atopic dermatitis. Clin Dermatol. 2003;21(3):183-92. https://doi.org/10.1016/S0738-081X(02)00363-2

17. Woods RK, Thien F, Raven J, et al. Prevalence of food allergies in young adults and their relationship to asthma, nasal allergies, and eczema. Ann Allergy Asthma Immunol. 2002;88(2):183-9. https://doi.org/10.1016/S1081-1206(10)61994-1

18. Sicherer SH, Sampson HA. Food hypersensitivity and atopic dermatitis: pathophysiology, epidemiology, diagnosis, and management. J Allergy Clin Immunol. 1999;104(3 Pt 2):S114-22. https://doi.org/10.1016/S0091-6749(99)70053-9

19. Worm M, Ehlers I, Sterry W, et al. Clinical relevance of food additives in adult patients with atopic dermatitis. Clin Exp Allergy. 2000;30(3):407-14. https://doi.org/10.1046/j.1365-2222.2000.00722.x

20. Breuer K, Wulf A, Constien A, et al. Birch pollen-related food as a provocation factor of allergic symptoms in children with atopic eczema/dermatitis syndrome. Allergy. 2004;59(9):988-94. https://doi.org/10.1111/j.1398-9995.2004.00493.x

21. Muraro A, Werfel T, Hoffmann-Sommergruber K, Roberts G, Beyer K, Bindslev-Jensen C, Cardona et al. EAACI food allergy and anaphylaxis guidelines. Diagnosis and management of food allergy. Allergy. 2014;69:1008-102531.

22. Caubet J-C, Eigenmann PA. Allergic triggers in atopic dermatitis. Immunol Allergy Clin N Am. 2010;30:289-307. https://doi.org/10.1016/j.iac.2010.06.002

23. Sampson HA. Role of immediate food hypersensitivity in the pathogenesis of atopic dermatitis. J Allergy Clin Immunol. 1983;71(5):473-80. https://doi.org/10.1016/0091-6749(83)90464-5

24. Sampson HA. Utility of food-specific IgE concentrations in predicting symptomatic food allergy. J Allergy Clin Immunol. 2001;107:891-6. https://doi.org/10.1067/mai.2001.114708

25. Turjanmaa K, Darsow U, Niggemann B, Rance F, Vanto T, Werfel T. EAACI/GA2LEN position paper: present status of the atopy patch test. Allergy. 2006;61:1377-84. https://doi.org/10.1111/j.1398-9995.2006.01136.x

26. Ying Luo, Guo-Qiang Z, Zhong-Yue Li. The diagnostic value of APT for food allergy in children: a systematic review and meta-analysis, Pedia.Allergy Immunol. 2019;1-11. wileyonlinelibrary.com/journal/pai C 2019 EAACl and John Wiley and Sons A/S.Published by John Wiley and Sons Ltd.

27. Flinterman $A E$, Knulst $A C$, Meijer $Y$, Bruijnzeel-Koomen $C A$, Pasmans SG. Acute allergic reactions in children with AEDS after prolonged cow's milk elimination diets. Allergy. 2006;61:370-4. https://doi.org/10.1111/j.1398-9995.2006.01018.x

28. Savage JH, Limb SL, Brereton NH, Wood RA. The natural history of peanut allergy: extending our knowledge beyond childhood. J Allergy Clin Immunol. 2007;120:717-9. https://doi.org/10.1016/j.jaci.2007.07.027

29. Scalabrin DM, Bavbek S, Perzanowski MS, et al. Use of specific IgE in assessing the relevance of fungal and dust mite allergens to atopic dermatitis: a comparison with asthmatic and nonasthmatic control subjects. J Allergy Clin Immunol. 1999;104(6):1273-9. https://doi.org/10.1016/S0091-6749(99)70024-2

30. Walker I. Causation of eczema, urticaria and angioneurotic edema. J Am Med Assoc. 1918;70:897. https://doi.org/10.1001/jama.1918.02600130001001

31. Tuft L, Heck VM. Studies in atopic dermatitis. IV. Importance of seasonal inhalant allergens, especially ragweed. J Allergy. 1952;23(6):528-40. https://doi.org/10.1016/0021-8707(52)90040-3

32. Tupker RA, De Monchy JG, Coenraads PJ, et al. Induction of atopic dermatitis by inhalation of house dust mite. J Allergy Clin Immunol. 1996;97(5):1064-70. https://doi.org/10.1016/S0091-6749(96)70259-2

33. Ring J, Darsow U, Gfesser M, et al. The 'atopy patch test' in evaluating the role of aeroallergens in atopic eczema. Int Arch Allergy Immunol. 1997;113(1-3):379-83.

https://doi.org/10.1159/000237609

34. Dai YS. Allergens in atopic dermatitis. Clin Rev Allergy Immunol. 2007;33(3):157-66. https://doi.org/10.1007/s12016-007-0042-7

35. van der Heijden FL, Wierenga EA, Bos JD, et al. High frequency of IL-4-producing CD41 allergen-specific T lymphocytes in atopic dermatitis lesional skin. J Invest Dermatol. 1991;97(3):389-94. https://doi.org/10.1111/1523-1747.ep12480966

36. Heinemann C, Schliemann-Willers S, Kelterer D, et al. The atopy patch test reproducibility and comparison of different evaluation methods. Allergy. 2002;57(7):641-5. https://doi.org/10.1034/j.1398-9995.2002.23438.x

37. Tan BB, Weald D, Strickland I, et al. Double-blind controlled trial of effect of house dust-mite allergen avoidance on atopic dermatitis. Lancet. 1996;347(8993):15-8. https://doi.org/10.1016/S0140-6736(96)91556-1

38. Koopman LP, van Strien RT, Kerkhof $M$, et al. Placebocontrolled trial of house dust mite-impermeable mattress covers: effect on symptoms in early childhood. Am J Respir Crit Care Med. 2002;166(3):307-13. https://doi.org/10.1164/rccm.2106026

39. Bussmann C, Bockenhoff $A$, Henke $H$, et al. Does allergenspecific immunotherapy represent a therapeutic option for patients with atopic dermatitis? J Allergy Clin Immunol. 2006;118(6):1292-8. https://doi.org/10.1016/j.jaci.2006.07.054 